\title{
Polymers: From Adsorption to Translocation - Topical Issue in Memoriam Loïc Auvray (1956-2016)
}

Published online: 25 October 2019 - (c) EDP Sciences / Società Italiana di Fisica / Springer-Verlag GmbH Germany, part of Springer Nature, 2019

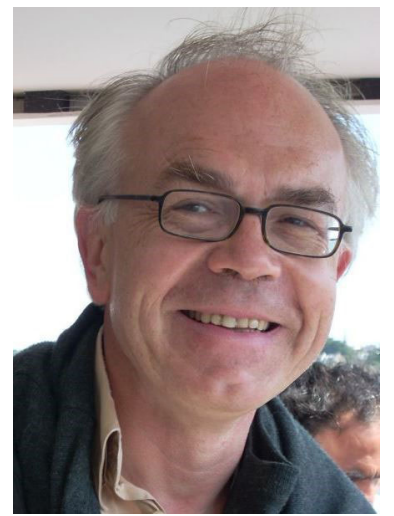

Loïc Auvray (1956-2016). Photo (CDR Univ. Evry.

The present Topical Issue Polymers: From Adsorption to Translocation honours the memory of Loïc Auvray (1956-2016).

Loïc Auvray made seminal contributions in Soft Matter and Biological Physics. After a first theoretical thesis under the supervision of Pierre-Gilles de Gennes on confined semi-flexible polymers at the Collège de France in Paris, he elucidated the bicontinuous structure of Winsor microemulsions in his PhD Thesis (1985) under the supervision of Christiane Taupin and Jean-Pierre Cotton, using X-rays and neutron scattering. He then joined the CNRS and the Laboratoire Léon Brillouin in Saclay to focus his research on adsorbed polymer layers. One of his major and noticeable achievements was to prove that the layers' structure is indeed self-similar as predicted by P.-G. de Gennes. He later moved in 2002 to the University Évry-Val-d'Essonne to found the Matériaux Polymères aux Interfaces laboratory where he initiated, developed and promoted original studies of the translocation of biopolymers across natural and artificial nanopores. By his interest in polymer translocation, Loïc not only promoted this transdisciplinary subject at the interface of biophysics and polymer science in his own laboratory, but contributed to the development of the field of nanopore sensing on a global level by inspiring with his unique sense of scientific comradeship and conviviality a series of unforgettable Summer Schools on Biosensing with Channels. In 2010, he moved back to Paris to head the Matière and Systèmes Complexes laboratory of the University Paris Diderot.

Loï had a major impact on generations of students and young researchers through his teaching of soft matter and his extraordinary enthousiasm for science. He also was a very active promotor of physics in high schools and one of the founders of the Olympiades de Physique in France.

Loïc passed away on June 8th, 2016 from ALS.

The variety of topics presented and the interdisciplinary approach of the articles in this Topical Issue of The European Physical Journal E (EPJE) perfectly reflect the enthusiasm, generosity and desire to connect researchers from different backgrounds that drove Loïc Auvray's career.

Jan C. Behrends, Jean-Marc Di Meglio, and Fabien Montel 